\title{
The role of metacognition in self-critical rumination: An investigation in individuals presenting with low self-esteem
}

\author{
Regular Article
}

Word count: 5,511

Date of second submission: 07/12/2015

\begin{abstract}
Daniel C. Kolubinski ${ }^{\mathrm{a}}$, Ana V. Nikčević ${ }^{\mathrm{b}}$, Jacqueline A. Lawrence ${ }^{\mathrm{a}}$, and Marcantonio M. Spada ${ }^{a}{ }^{*}$
\end{abstract}

\footnotetext{
${ }^{a}$ Division of Psychology, School of Applied Sciences, London South Bank University, London, UK

${ }^{\mathrm{b}}$ Department of Psychology, Kingston University, Kingston upon Thames, UK

* Correspondence to: Professor Marcantonio Spada, Division of Psychology, School of Applied Sciences, London South Bank University, London, United Kingdom. Tel. +44 (0)20 7815 7815, e-mail spadam@lsbu.ac.uk.
}

The final publication is available at Springer via http://dx.doi.org/10.1007/s10942-015-0230-y 


\section{Abstract}

Background: No research, to date, has directly investigated the role of metacognition in selfcritical rumination and low self-esteem. Aim: To investigate the presence of metacognitive beliefs about self-critical rumination; the goal of self-critical rumination and its stop signal; and the degree of detachment from intrusive self-critical thoughts. Method: Ten individuals reporting both a self-acknowledged tendency to judge themselves critically and having low self-esteem were assessed using metacognitive profiling, a semi-structured interview. Results: All participants endorsed both positive and negative metacognitive beliefs about self-critical rumination. Positive metacognitive beliefs concerned the usefulness of selfcritical rumination as a means of improving cognitive performance and enhancing motivation. Negative metacognitive beliefs concerned the uncontrollability of self-critical rumination and its negative impact on mood, motivation and perception of self-worth. The primary goal of engaging in self-critical rumination was to achieve a better or clearer understanding of a given trigger situation or to feel more motivated to resolve it. However, only four participants were able to identify when this goal had been achieved, which was if the trigger situation were not to occur again. Participants unanimously stated that they were either unable to detach from their self-critical thoughts or could do so some of the time with varying degrees of success. More often than not, though, self-critical thoughts were viewed as facts, would rarely be seen as distorted or biased, and could take hours or days to dissipate. Conclusions: These findings provide preliminary evidence that specific facets of metacognition play a role in the escalation and perseveration of self-critical rumination.

Key words: metacognition; self-critical rumination; self-critical thoughts; self-criticism; selfesteem. 


\section{Introduction}

\subsection{Self-esteem and psychopathology}

Self-esteem is one of the oldest and most studied concepts in the field of psychology (Cameron, MacGregor, \& Kwang, 2013; Mruk, 2013; Trzesniewski, Donnellan, \& Robins, 2013; Zeigler-Hill, 2013). This has meant that this concept has developed different definitions (Brown \& Marshall, 2006; Moller, Friedman, \& Deci, 2006; Mruk, 2013). The term 'self-esteem' has come to refer to a personality variable that represents how individuals generally evaluate themselves (trait self-esteem), a self-evaluative reaction to specific emotionally-laden events (state self-esteem), and an evaluation of personal abilities and attributes (domain-specific self-esteem) (Brown \& Marshall, 2006). In each of these areas, when the evaluation is positive and the individual expresses a favourable opinion of him- or herself, then that individual is said to experience high self-esteem, whereas low self-esteem emerges when an individual has a fundamentally uncertain or negative view of him- or herself, whether globally or specifically.

Although low self-esteem is not in itself considered a psychological disorder, it does play a significant role in psychopathology. In the fourth edition of the Diagnostic and Statistical Manual of Mental Disorders (DSM-IV-TR; American Psychiatric Association, 2000), low self-esteem was either a diagnostic criteria for, or associated feature of, 24 different mental health disorders (O’Brien, Bartoletti, \& Leitzel, 2006). In a recent metaanalysis of longitudinal studies of anxiety and depression, Sowislo and Orth (2013) concluded that low self-esteem was both a significant predictor and causal factor of both conditions.

\subsection{The cognitive therapy model of self-esteem}

In the cognitive therapy model of self-esteem (Fennell, 1997), which is based on Beckian schema theory (Beck, 1967), low self-esteem is defined as a global image of the self, 
which is persistent, derogatory, habitual and largely outside of awareness, and is referred to as the bottom line (e.g. "I'm worthless”). It is postulated that rules for living are developed in order to keep the bottom line hidden from the view of others (e.g. "I must succeed at everything I do"). When a situation arises where the rule may be violated, such as potential or actually failing a task, the bottom line becomes activated fuelling predictions of negative consequences, such as judgment from or punishment by others. This leads to a rise in anxiety and associated self-defeating and safety-seeking behaviours, such as withdrawal, self-focus, or reassurance seeking; these short-term behaviours, however, serve to confirm the 'truth' of the bottom line. Focusing on the bottom line increases self-critical intrusive thoughts leading to a lowering of mood. Fennell (1997) proposes that the bottom line becomes more easily activated when mood is low, which then strengthens a vicious cycle of negative thinking, anxiety, unhelpful behaviours, self-criticism and depressed mood.

Using this model as a guide, the aims of cognitive therapy are to weaken old, negative beliefs and to establish a more positive alternative. This is done by re-evaluating negative predictions, reducing symptoms of anxiety, changing behaviour, shifting perceptual bias and reducing self-critical thinking (Fennell, 1997). Evidence has shown that cognitive therapy interventions based on this model may indeed help clients improve self-esteem (Pack \& Condren, 2014; Waite, McManus, \& Shafran, 2012).

\subsection{Self-critical rumination: An important construct in understanding low self-esteem?}

A prominent feature of Fennell's cognitive model of self-esteem (1997) is the heightened presence of self-criticism in those with low self-esteem. Self-criticism is defined as "a form of negative self-evaluation in which judgmental, condemning, and attacking thoughts are directed to the self, especially in the context of perceived mistakes, failures, and inability to live up to one’s own or others' standards” (Smart, Peters, \& Baer, 2015, p. 1). Higher levels of self-criticism have been linked to low self-esteem (Grzegorek, Slaney, 
Franze, \& Rice, 2004; Heimpel, Wood, Marshall, \& Brown, 2002) and to several forms of psychopathology as well as impaired functioning in adulthood (Gilbert, Clarke, Hempel, Miles, \& Irons, 2004; Gilbert \& Procter, 2006; Shahar, 2015; Smart et al., 2015). However, the tendency to engage in self-criticism is common and various researchers have suggested that moderate 'doses' of it can serve to self-correct, prevent future errors, and improve oneself (Driscoll, 1989; Gilbert, 1997).

It has recently been argued that self-criticism may become problematic if it escalates to a ruminative style of thinking (Smart et al., 2015). Rumination is a cognitive process that involves self-focused attention, repetitive focus on one's negative affect as well as its causes and consequences (Nolen-Hoeksema, Wisco, \& Lyubomirsky, 2008; Treynor, Gonzalez, \& Nolen-Hoeksema, 2003) and has been associated with the onset and maintenance of symptoms of psychopathology because it enhances the emotional states related to the content of thought and interferes with effective problem-solving (Nolen-Hoeksema et al., 2008).

Rumination, particularly the tendency to brood by thinking anxiously or gloomily, has been shown to moderate the effects of self-criticism on levels of suicidality and depression (O’Connor \& Noyce, 2008; Spasojević \& Alloy, 2001) as well as the effects of low selfesteem on depression (Kuster, Orth, \& Meier, 2012). More recently, Smart and colleagues (2015) have provided evidence to suggest that 'self-critical rumination', which refers to the process of ruminating specifically on the content of self-critical thoughts, may be a separate construct from that measured by general measures of rumination, such as the Rumination Response Scale (Treynor et al., 2003).

\subsection{Self-critical rumination: Could metacognition be a driver?}

Although Fennell’s (1997) cognitive therapy model goes a long way to explain the crucial role of negative beliefs about the self in propagating low self-esteem, it fails to operationalise the mechanisms that bring to 'focus on the bottom line' and maintain attention 
on self-critical intrusive thoughts leading to a lowering of mood. In other words, Fennell's model appears to ignore the role of rumination, particularly in the form of self-critical rumination, in maintaining self-critical intrusive experiences that are so crucial for the lowering of self-esteem.

A theoretical framework which may be useful in shedding light on the mechanisms driving and maintaining self-critical rumination is the Self-Regulatory Executive Function (SREF) model described by Wells and Matthews $(1994,1996)$. This model emphasizes the key role played by the mechanisms which generate, monitor and maintain intrusive experiences, rather than focusing upon the content of such experiences (Wells, 2009). From this perspective psychological distress is rooted in the selection and implementation of coping styles, based on metacognitive beliefs (beliefs about our internal events and how to control them), which focus attention towards distress congruent information (e.g. environmental threats) establishing a vicious cycle where faulty coping style 'blueprints' are consistently applied to alleviate distressing experiences, yet a successful resolution fails to be achieved. Over time the combination of applying the same blueprints leads to the development of an internal dissonance characterized by negative appraisals towards the selected coping styles and internal experiences more generally.

The S-REF model also distinguishes between two different modes of processing thoughts: object mode and metacognitive mode (Wells, 2009). In object mode, thoughts are not distinguished from sensory stimuli. Both inner and outer events are treated equally in an undifferentiated consciousness and responded to accordingly. In the metacognitive mode, however, thoughts are consciously perceived as being separate from the self and the world and can instead be observed by the individual and evaluated objectively for their veracity.

The S-REF model has already been applied to conceptualising Generalised Anxiety Disorder, Major Depressive Disorder, Obsessive-Compulsive Disorder, Post-Traumatic 
Stress Disorder and problem drinking with interventions based on this framework having been found to be effective (for a review see Wells, 2009, 2013). In the case of self-critical rumination, it may be valuable to gain a better understanding of aspects of metacognition that may promote the engagement in this activity (as a coping style) with consequent worsening of self-esteem.

\subsection{Aims of the current study}

To date, no research has been conducted on investigating aspects of metacognition involved in the activation and perseveration of self-critical rumination. In the early stages of research, metacognition is typically explored using the metacognitive profiling interview (Wells, 2000). This interview has already been successfully employed to identify crucial facets of metacognition in desire thinking (Caselli \& Spada, 2010), distress in Parkinson's disease (Fernie et al., 2015), pathological procrastination (Fernie \& Spada, 2008), problem

drinking (Spada \& Wells, 2006), problem gambling (Spada et al., 2014), rumination (Papageorgiou \& Wells, 2001) and smoking (Nikčević \& Spada, 2010). In line with a metacognitive conceptualization we thus aimed to profile: (1) the presence of specific metacognitive beliefs about self-critical rumination; (2) the goal of self-critical rumination, and its start and stop signals; and (3) the degree of detachment from intrusive self-critical thoughts. 


\section{Method}

\subsection{Participants}

The Research Ethics Committee at London South Bank University reviewed all of the material for this study, including the interview template, marketing materials and process for recording and transcribing the interviews. Twelve individuals completed the study (3 male; mean age 23.9 years, $\mathrm{SD}=4.6$ years, range $18-33$ years). Average scores on the Rosenberg Self-Esteem Scale (Rosenberg, 1965) were 12.9 (range=11-16; standard deviation=1.9) indicating predominantly low levels of self-esteem in the sample (the cut off for low selfesteem is a score of 14 or below). Participants identified their ethnicity as: Black British (3); Asian (3); White British (2); White European (1); and Other/Mixed (2). Inclusion criteria were: (1) reporting low self-esteem; and (2) possessing a self-acknowledged tendency to judge oneself critically. Exclusion criteria were: (1) being currently engaged in psychotherapy; and (2) being on a course of medication related to a diagnosis of a mood disorder. The research team surmised that active treatment for a mood disorder could impact the level of self-critical thinking and/or self-critical rumination or could provide insights that might change the way the participant views their self-critical thoughts. Two participants did not meet the eligibility criteria, as levels of self-esteem were considered too high for this study. Their interviews were discarded.

\subsection{Procedure and interview}

Participants were recruited after responding to a flyer placed in university and work settings asking for individuals who regularly experience low self-esteem, with high levels of self-criticism. Recruitment occurred between January and July 2015 with all participants agreeing to take part in the study. Participants were interviewed by the first author, a psychotherapist specialized in cognitive behavior therapy, who was supervised by the fourth author, a psychologist and trained metacognitive therapy practitioner, in using the 
metacognitive profiling interview (Wells, 2000) adapted to focus specifically on self-critical rumination. The interview, which was audio recorded, lasted approximately 30 minutes and was conducted and transcribed by the first author, who then generated a list of responses to the interview questions. The research team then collaborated to identify the positive and negative metacognitive beliefs related to self-critical rumination. The quotes presented were synthetic extracts identified by the evaluators (first, second and fourth author). No marked discrepancies were observed in the identification and selection of these synthetic extracts.

Each participant was interviewed about their experience of self-critical rumination following the failure of a task or an error of commission. All participants were asked to recount a recent episode that triggered self-critical rumination and the interview consisted of three stages (see Table 1): The first stage explored positive and negative metacognitive beliefs by asking about the advantages and disadvantages of engaging in self-critical rumination. The second stage enquired about the goal of self-critical rumination and how to identify when this goal would be accomplished (the stop signal). The third stage examined the degree of detachment from intrusive self-critical thoughts.

\section{Results}

Situations recalled by participants which triggered self-critical rumination included variations of achieving a poor grade on an assignment or exam, making a mistake at work, having an awkward social interaction with a friend, having an argument with a partner, and failing a test (e.g. a driving test). All participants were able to identify advantages (i.e. positive beliefs) and disadvantages (i.e. negative beliefs) of self-critical rumination. The content of these positive and negative metacognitive beliefs about self-critical rumination are displayed in Table 2. Positive metacognitive beliefs concerned the usefulness of engaging in self-critical rumination as a means of improving cognitive performance (particularly judgement) and enhancing motivation. Negative metacognitive beliefs concerned the 
uncontrollability of self-critical rumination and its negative impact on mood, motivation and perception of self-worth.

In response to the question concerning the goal of engaging in self-critical rumination, eight participants stated the desired goal for engaging in self-critical rumination was to achieve a better or clearer understanding of a given trigger situation or to feel more motivated to resolve it. However, only four participants endorsed being able to identify when their goal had been achieved. The most common method of determining that the goal had been achieved was if the trigger situation were not to occur again.

The last three questions in the interview involved investigating the relationship that the participants have with their self-critical thoughts (self-criticism). Nine out of the 10 participants reported that they either definitely, or more often than not, identified their selfcritical thoughts as facts. Four of these participants stated that they were unable to view these thoughts as cognitive distortions, whilst four considered them to be distortions either some of the time or after the passage of time. One participant was able to acknowledge viewing selfcritical thoughts as distortions in addition to viewing them as facts, but also stated that confidence in the ability to tell the difference between the two was low. Lastly, all participants were in agreement that detaching from self-critical thoughts in order to observe them without identifying with them (being in metacognitive mode) was particularly challenging with only two participants reporting being able to do so some of the time.

\section{Discussion}

\subsection{Findings}

The findings of this study suggest that specific facets of metacognition may play a role in the activation and perseveration of self-critical rumination, a possible driver of low self-esteem. The results are consistent with Wells \& Matthews' $(1994,1996)$ S-REF model and align themselves to previous findings employing metacognitive profiling. 
Positive metacognitive beliefs concerned the usefulness of engaging in self-critical rumination as a means of improving cognitive performance (particularly judgement) and enhancing motivation. These beliefs may justify the activation of self-critical rumination as a means of 'mental' problem-solving and coping following real or imagined episodes of failure, and/or awkward social and interpersonal situations. Negative metacognitive beliefs concerned the uncontrollability of self-critical rumination and its negative impact on mood, motivation and perception of self-worth. The S-REF model (Wells, 2000) distinguishes between two categories of negative metacognitive beliefs: danger/harm and uncontrollability. It also suggests that psychological disturbance occurs when coping strategies (in this case, self-critical rumination) become perseverative and are perceived as uncontrollable (Wells \& Matthews, 1994). Consistent with both of these aspects of the S-REF model, negative metacognitive beliefs conveyed by the participants in this study may play a role in propagating negative affect and lead to a perseveration of self-critical rumination, because the individual remains locked in object mode, perceiving the self-critical thoughts both as facts and potentially harmful without being able to detach from them.

The majority of participants engaged in self-critical rumination as a coping strategy to achieve a better or clearer understanding of a given trigger situation or to feel more motivated to resolve it. However, only four participants were able to identify when the goal had been achieved. The most common method of measuring whether the goal had been achieved was if the trigger situation were not to occur again; a near-impossible task, with no endgame since the individual is unable to predict the future. Herein also lies a clear contradiction between the perception of the benefits of engaging in self-critical rumination (underscored by positive metacognitive beliefs) and the difficulties in knowing when to stop, because the activity itself lowers mood and affects judgement (so the ‘stop’ signal is not achieved). Equally, relying on the stop signal that trigger situations will not re-occur at any point in time is a high risk 
strategy with negligible success potential. The incongruence between the goals and stop signals identified may explain why self-critical rumination begins and why it is difficult to discontinue once initiated. In support of this view eight of the participants reported that they would engage in self-critical rumination from several hours to several days following a perceived mistake or failure. In this respect self-critical rumination shows some similarity with other forms of perseverative thinking such as desire thinking, rumination, and worry (Caselli et al., 2010; Wells \& Papageorgiou, 1995; Wells, 2000).

The final phase of the interview asked participants about their ability to distance themselves from their self-critical thoughts and see them as distorted or biased thinking rather than as facts. Self-critical thoughts have been described as an 'inner voice' that an individual repeatedly hears denigrating him or her (Gilbert et al., 2004; Noordenbos, Aliakbari, \& Campbell, 2014), from which it can be difficult to detach (Whelton \& Greenberg, 2005). In this study, the participants unanimously stated that they were either unable to detach from their self-critical thoughts or could do so some of the time with varying degrees of success. More often than not, though, self-critical thoughts were viewed as facts and would rarely be seen as distorted or biased.

The evidence suggests that individuals with self-identified low self-esteem may operate almost exclusively in object mode with respect to their self-critical thoughts and appear to have a lack of awareness about the ability to experience thoughts in metacognitive mode. This finding supports previous research on the relationship between psychopathology and lack of awareness of how to detach from negative intrusive thoughts as described in metacognitive theory (Wells, 2009).

\subsection{Improving low self-esteem: A role for Metacognitive Therapy?}

One of the limitations of the cognitive therapy model of self-esteem (Fennel, 1997) is that it does not conceptualise and target self-critical rumination. The findings from our study 
suggest that the techniques and principles of metacognitive therapy (Wells, 2009) may thus be beneficial in helping patients discontinue self-critical rumination. The adapted metacognitive profiling interview presented could help elicit useful information about metacognitive beliefs and metacognitive plans involved in both the initiation and maintenance of self-critical rumination. Metacognitive beliefs could be questioned and modified using re-attributional techniques (Wells, 2009) whilst the role of self-criticism in affecting cognitive-emotional states and behavioural control could be reviewed. In addition, a variety of strategies could be employed to actively interrupt self-critical rumination, such as attention training and detached mindfulness, which have already been employed successfully in treating rumination in depression and worry in generalized anxiety disorder (Wells, 2013).

A central benefit of interrupting self-critical rumination could be that of fostering 'unconditional self-acceptance' (Ellis, 1996), the achievement of full acceptance of oneself irrespectively of personal ability or external approval. Indeed evidence has suggested that higher levels of self-esteem are related to unconditional self-acceptance (Davies, 2006; Thompson \& Waltz, 2008).

\subsection{Limitations and directions for future research}

There are several limitations to this study that need to be acknowledged when interpreting these findings. Firstly, the sample size was small and predominantly female. Secondly, each participant was asked to recall a recent event and so responses were based on retrospective self-reporting. Thirdly, levels of trait self-criticism, rumination and/or the selfcritical rumination were not measured. Fourthly, individuals with genuine high self-esteem or fragile high self-esteem (where positive judgments of the self are either contingent on external criteria, incongruent with low emotional and implicit feelings toward the self, or unstable over time) were not investigated (Borton et al., 2012; Kernis, Lakey, \& Heppner, 2008). Lastly, the structured interview, although widely used and useful to elicit relevant 
aspects of metacognition, may also introduce biases, both by the participants' self-reports and investigator evaluations. This limitation also meant that implicit self-esteem could not be measured, because inclusion criteria were only based on self-identified low self-esteem, which makes it explicit (Bosson, Swann, \& Pennebaker, 2000; Jordan et al., 2006). Future research will benefit from widening the sample population and exploring real-time situations where participants are faced with experiences that activate their self-critical thoughts (content) and rumination (process). It will also be important to explore the link between metacognition and both types of high self-esteem.

In conclusion, we believe that this study provides useful information regarding the role of metacognition with respect to self-critical rumination in low self-esteem, and the potential relevance of the S-REF model. Based on this study, future research could provide a more thorough understanding of how metacognition may drive self-critical rumination, whether positively or negatively, which could have significant therapeutic benefits.

\section{Compliance with Ethical Standards:}

Funding: This study did not receive any funding.

Conflict of Interest: The authors declare that they have no conflict of interest. 


\section{References}

American Psychiatric Association. (2000). Diagnostic and statistical manual of mental health disorders (4th ed., text rev.). Washington, DC: Author.

Beck, A. T. (1967). Depression: Clinical, Experimental and Theoretical Aspects. New York, NY: Harper \& Row.

Borton, J. L. S., Crimmins, A. E., Ashby, R. S., \& Ruddiman, J. F. (2012). How do individuals with fragile high self-esteem cope with intrusive thoughts following ego threat? Self and Identity, 11, 16-35.

Bosson, J. K., Swann, W. B., \& Pennebaker, J. W. (2000). Stalking the perfect measure of implicit self-esteem: The blind men and the elephant revisited? Journal of Personality and Social Psychology, 79, 631-643.

Brown, J. D., \& Marshall, M. A. (2006). The three faces of self-esteem. In M. H. Kernis (Ed.), Self-esteem issues and answers: A sourcebook of current perspectives (pp. 4-9). New York, NY: Psychology Press.

Cameron, J., MacGregor, J., \& Kwang, T. (2013). Badge of honor or mark of shame: Selfesteem as an interpersonal signal. In V. Zeigler-Hill (Ed.), Self-esteem (pp. 145-162). London: Psychology Press.

Caselli, G., Ferretti, C., Leoni, M., Rebecchi, D., Rovetto, F., \& Spada, M. M. (2010). Rumination as a predictor of drinking behaviour in alcohol abusers: A prospective study. Addiction, 105, 1041-1048.

Driscoll, R. (1989). Self-condemnation: A comprehensive framework for assessment and treatment. Psychotherapy: Theory, Research, Practice, Training, 26, 104-111.

Fennell, M. J. V. (1997). Low self-esteem: A cognitive perspective. Behavioural and Cognitive Psychotherapy, 25, 1-25.

Fernie, B. A., \& Spada, M. M. (2008). Metacognitions about procrastination: A preliminary investigation. Behavioural and Cognitive Psychotherapy, 36, 359-364.

Fernie, B. A., Spada, M. M., Chaudhuri, K. R., Klingelhoefer, L., \& Brown, R. G. (2015). [In press] Thinking about motor fluctuations: An examination of metacognitions in Parkinson's disease. Journal of Psychosomatic Research.

Gilbert, P. (1997). Overcoming Depression: A Self-guide Using Cognitive Behavioural Techniques. London: Robinsons.

Gilbert, P., Clarke, M., Hempel, S., Miles, J. N. V, \& Irons, C. (2004). Criticizing and reassuring oneself: An exploration of forms, styles and reasons in female students. The British Journal of Clinical Psychology, 43, 31-50. 
Gilbert, P., \& Procter, S. (2006). Compassionate mind training for people with high shame and self-criticism: Overview and pilot study of a group therapy approach. Clinical Psychology and Psychotherapy, 13, 353-379.

Grzegorek, J. L., Slaney, R. B., Franze, S., \& Rice, K. G. (2004). Self-criticism, dependency, self-esteem, and grade point average satisfaction among clusters of perfectionists and nonperfectionists. Journal of Counseling Psychology, 51, 192-200.

Heimpel, S. A., Wood, J. V., Marshall, M. A., \& Brown, J. D. (2002). Do people with low self-esteem really want to feel better? Self-esteem differences in motivation to repair negative moods. Journal of Personality and Social Psychology, 82, 128-147.

Jordan, C. H., Logel, C., Spencer, S. J., \& Zanna, M. P. (2006). Nonconscious self-esteem: Is there something you're not telling yourself? In M. H. Kernis (Ed.), Self-esteem issues and answers: A sourcebook of current perspectives1 (pp. 60-68). New York, NY: Psychology Press.

Kernis, M. H., Lakey, C. E., \& Heppner, W. L. (2008). Secure versus fragile high self-esteem as a predictor of verbal defensiveness: Converging findings across three different markers. Journal of Personality, 76, 477-512.

Kuster, F., Orth, U., \& Meier, L. L. (2012). Rumination mediates the prospective effect of low self-esteem on depression: A five-wave longitudinal study. Personality and Social Psychology Bulletin, 38, 747-759.

Moller, A. C., Friedman, R., \& Deci, E. L. (2006). A self-determination theory perspective on the interpersonal and intrapersonal aspects of self-esteem. In M. H. Kernis (Ed.), Selfesteem issues and answers: A sourcebook of current perspectives (pp. 188-194). New York, NY: Psychology Press.

Mruk, C. J. (2013). Self-esteem and positive psychology: Research, theory, and practice (4th ed.). New York, NY: Springer Publishing Company.

Nikčević, A. V., \& Spada, M. M. (2010). Metacognitions about smoking: A preliminary investigation. Clinical Psychology \& Psychotherapy, 17, 536-542.

Nolen-Hoeksema, S., Wisco, B. E., \& Lyubomirsky, S. (2008). Rethinking rumination. Perspectives on Psychological Science, 3, 400-424.

Noordenbos, G., Aliakbari, N., \& Campbell, R. (2014). The relationship among critical inner voices, low self-esteem, and self-criticism in eating disorders. Eating Disorders, 22, 337-51.

O’Brien, E. J., Bartoletti, M., \& Leitzel, J. D. (2006). Self-Esteem, psychopathology, and psychotherapy. In M. H. Kernis (Ed.), Self-esteem issues and answers: A sourcebook of current perspectives (pp. 306-315). New York, NY: Psychology Press.

O’Connor, R. C., \& Noyce, R. (2008). Personality and cognitive processes: Self-criticism and different types of rumination as predictors of suicidal ideation. Behaviour Research and Therapy, 46, 392-401. 
Pack, S., \& Condren, E. (2014). An evaluation of group cognitive behaviour therapy for low self-esteem in primary care. The Cognitive Behaviour Therapist, 7(e7), 1-10.

Papageorgiou, C., \& Wells, A. (2001). Metacognitive beliefs about rumination in recurrent major depression. Cognitive and Behavioral Practice, 8, 160-164.

Rosenberg, M. (1965). Society and the Adolescent Self-Image. Princeton, NJ: Princeton University Press.

Shahar, G. (2015). Erosion: The psychopathology of self-criticism. New York, NY: Oxford University Press.

Smart, L. M., Peters, J. R., \& Baer, R. A. (2015). Development and validation of a measure of self-critical rumination. Assessment, 1-12.

Sowislo, J. F., \& Orth, U. (2013). Does low self-esteem predict depression and anxiety? A meta-analysis of longitudinal studies. Psychological Bulletin, 139, 213-40.

Spada, M. M., Giustina, L., Rolandi, S., Fernie, B. A., \& Caselli, G. (2014). Profiling metacognition in gambling disorder. Behavioural and Cognitive Psychotherapy, 1-9.

Spada, M. M., \& Wells, A. (2006). Metacognitions about alcohol use in problem drinkers. Clinical Psychology \& Psychotherapy, 13, 138-143.

Spasojević, J., \& Alloy, L. B. (2001). Rumination as a common mechanism relating depressive risk factors to depression. Emotion, 1, 25-37.

Treynor, W., Gonzalez, R., \& Nolen-Hoeksema, S. (2003). Rumination reconsidered: A psychometric analysis. Cognitive Therapy and Research, 27, 247-259.

Trzesniewski, K. H., Donnellan, M. B., \& Robins, R. W. (2013). Development of selfesteem. In V. Zeigler-Hill (Ed.), Self-esteem (pp. 60-79). London, UK: Psychology Press.

Waite, P., McManus, F., \& Shafran, R. (2012). Cognitive behaviour therapy for low selfesteem: A preliminary randomized controlled trial in a primary care setting. Journal of Behavior Therapy and Experimental Psychiatry, 43, 1049-1057.

Wells, A. (2000). Emotional Disorders and Metacognition: Innovative Cognitive Therapy. Chichester, UK: Wiley.

Wells, A. (2009). Metacognitive Therapy for Anxiety and Depression. New York, NY: Guilford Press.

Wells, A. (2013). Advances in metacognitive therapy. International Journal of Cognitive Therapy, 6, 186-201.

Wells, A., \& Matthews, G. (1994). Attention and Emotion: A Clinical Perspective. Hove, UK: Erlbaum. 
Wells, A., \& Matthews, G. (1996). Modelling cognition in emotional disorder: The S-REF model. Behaviour Research and Therapy, 34, 881-888.

Wells, A., \& Papageorgiou, C. (1995). Worry and the incubation of intrusive images following stress. Behaviour Research and Therapy, 33, 579-583.

Whelton, W. J., \& Greenberg, L. S. (2005). Emotion in self-criticism. Personality and Individual Differences, 38, 1583-1595.

Zeigler-Hill, V. (2013). The importance of self-esteem. In V. Zeigler-Hill (Ed.), Self-esteem (pp. 1-20). London, UK: Psychology Press. 
Table 1: Metacognitive profiling template.

\begin{tabular}{|c|c|}
\hline \multicolumn{2}{|c|}{ Antecedents } \\
\hline & $\begin{array}{l}\text { 'When you felt low after making a mistake, failing a task or doing something that } \\
\text { you shouldn't have, did you have any judgmental thoughts about your worth or } \\
\text { being worthless?' } \\
\text { Did you notice that you were ruminating about something? What was your } \\
\text { rumination like?' }\end{array}$ \\
\hline \multicolumn{2}{|r|}{$\begin{array}{l}\text { Positive metacognitive beliefs about self-critical rumination } \\
\text { - 'Do you think there are any advantages to repeatedly judging yourself or being self- } \\
\text { critical?' } \\
\text { - ' 'If so, what are the advantages?' }\end{array}$} \\
\hline \multicolumn{2}{|r|}{$\begin{array}{l}\text { Negative metacognitive beliefs about self-critical rumination } \\
\text { - 'Do you think there are any disadvantages to repeatedly judging yourself or being } \\
\text { - } \text { self-critical?' } \\
\text { - 'If so, what are the disadvantages?' } \\
\text { - 'Can judging yourself or being self-critical in certain ways be harmful or } \\
\text { - ' 'In what way could it be dangerous or harmful?' }\end{array}$} \\
\hline & $\begin{array}{l}\text { of self-critical rumination and stop signal } \\
\text { 'What was your goal in being repeatedly self-critical? } \\
\text { 'How did you know that you had accomplished your goals?' } \\
\text { 'What was the effect of your coping strategies on your feelings and thoughts?' }\end{array}$ \\
\hline & $\begin{array}{l}\text { ment from intrusive self-critical thoughts } \\
\text { 'Did you accept your self-critical thoughts and judgments as facts, based in real } \\
\text { 'Could you see your self-critical thoughts as reflecting the reality of a given }\end{array}$ \\
\hline
\end{tabular}


Table 2: Positive and negative metacognitive beliefs of about self-critical rumination.

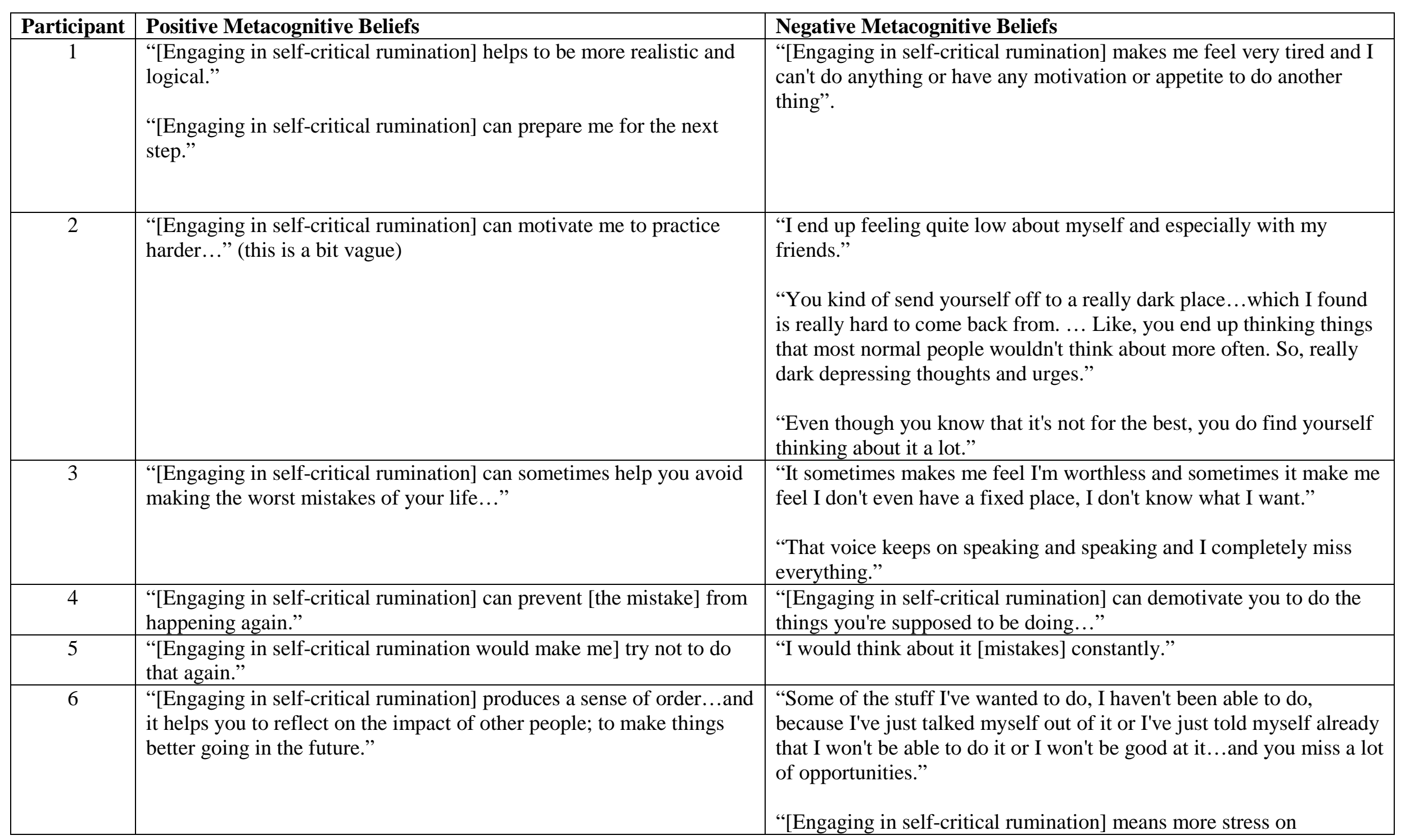




\begin{tabular}{|c|l|l|}
\hline & & you...and can lead you ultimately to depression.” \\
\hline 7 & "[If you engage in self-critical rumination,] you will be less arrogant.” & "[Engaging in self-critical rumination] makes you stressed.” \\
\hline 9 & $\begin{array}{l}\text { "[Engaging in self-critical rumination] is good for finding clarity.” } \\
\text { "You get stuck in a situation where you keep trying to think about } \\
\text { what's gone wrong and you want to make it better but you get stuck in } \\
\text { the situation where you can't and you feel trapped in a way.” }\end{array}$ & $\begin{array}{l}\text { "[Engaging in self-critical rumination] knocks your confidence... } \\
\text { stops you from doing things...lower your mood.” } \\
\text { improve?” }\end{array}$ \\
\hline 10 & $\begin{array}{l}\text { "Next time you can actually stop and think before saying everything } \\
\text { you want...” }\end{array}$ & $\begin{array}{l}\text { "I keep on being stuck on that thought, even if it's completely } \\
\text { useless....and I feel a kind of distress over that.” }\end{array}$ \\
\hline
\end{tabular}

